\title{
A pesca de pequena escala no rio Madeira pelos desembarques ocorridos em Manicoré (Estado do Amazonas), Brasil
}

\author{
Renato Soares CARDOSO ${ }^{1}$, Carlos Edwar de Carvalho FREITAS²
}

\section{RESUMO}

O trabalho teve como objetivo analisar o desembarque da pesca comercial na região do Médio rio Madeira, tendo como área focal o município de Manicoré, buscando identificar as espécies explotadas, os locais de pesca e sua contribuição para o abastecimento local de pescado. O desembarque foi amostrado diariamente, utilizando questionários aplicados aos pescadores após a comercialização do pescado. Foram desembarcadas no ano de 2002 aproximadamente 225,4 toneladas de pescado. Canoas motorizadas efetuaram mais expediçóes de pesca, entretanto os barcos de pesca desembarcaram uma maior produção. Os valores médios de desembarque foram de 11,2; 5,4 e 2,4 toneladas por mês para barcos, canoas e compradores de pescado respectivamente, sendo as capturas compostas por 32 espécies ou grupo de espécies, sendo jaraqui (Semaprochilodus spp), pacu (Mylossoma duriventre), curimatá (Prochilodus nigricans), sardinha (Triportheus spp) e jatuarana (Brycon spp), responsáveis por $75 \%$ do pescado desembarcado. Foram identificados 32 locais de pesca, sendo os mais explotados os rios Madeira e Manicoré, os lagos Acará e Boquerão e o igarapé Matupiri.

PaLAVRaS-ChaVE: Amazônia; Pesca interior; Locais de pesca; Espécies explotadas; Rio Madeira

\section{Small-scale fishery at Madeira River by fish landings in Manicoré city (Amazon State), Brazil.}

\begin{abstract}
The study aimed to analyze the landing of commercial fishing in Middle Madeira River, near Manicoré city, identifying the exploited species, fishing grounds and the contribution for the local supplying of fish. Fish landings were sampled daily, using questionnaires, given to fishermen after the fish sale. In 2002, 225.4 tons of fish were landed in Manicoré city. Motorized canoes undertook more fishing trips, but the higher fish landings were accomplished by boats. Mean values of fish landings were 11.2 tons/month, 5.4 tons/month and 2.4 tons/month for boats, motorized canoes and fish purchasers, respectively. 32 species or group of species were landed, with a predominance of jaraqui (Semaprochilodus spp), pacu (Mylossoma duriventre), curimatá (Prochilodus nigricans), sardinha (Triportheus spp) e jatuarana (Brycon spp), responsible for $75 \%$ of fish production. 32 fishing grounds were identified and the most exploited were the Madeira and Manicoré rivers, Acará and Boquerão lakes and the Matupiri stream.
\end{abstract}

KEY-WORDS: Amazonian; Artisanal fishing; Fishing grounds; Exploited species; Madeira River

\footnotetext{
1 Doutorando em Biologia de Água Doce e Pesca Interior. Instituto Nacional de Pesquisas da Amazônia - INPA, rsconpisci@yahoo.com.br

2 Universidade Federal do Amazonas, cefreitas@ufam.edu.br
} 


\section{INTRODUÇÃO}

$\mathrm{Na}$ região amazônica coexistem cinco diferentes tipos de pescarias: a pesca de subsistência, praticada por pescadores polivalentes das comunidades das várzeas do rio Amazonas e seus afluentes; a pesca comercial multiespecífica, exercida por pescadores monovalentes citadinos e que abastece os principais centros urbanos regionais; a pesca industrial no estuário amazônico, voltada para a captura de bagres, principalmente piramutaba (Brachyplatystoma vaillantii); a pesca de reservatório praticada nos lagos de Balbina e Tucuruí; e a pesca de peixes ornamentais, efetuada em maior escala na região do rio Negro (Furtado, 1993; Barthem et al., 1997; Santos, 1999).

As características artesanais da atividade são acentuadas devido a multiespecificidade da exploração pesqueira regional e pela utilização de uma variedade de apetrechos de pesca, muitos deles derivados de artigos indígenas e que foram incorporados à pesca comercial pelos pescadores locais (Petrere Jr., 1978; Batista, 1998). Além disso, a captura de pescado é efetuada nos mais variados ambientes lóticos e lênticos. A utilização, em maior ou menor intensidade desses ambientes está ligada ao ciclo hidrológico e às características ecológicas das espécies-alvo e afetam diretamente as estratégias das pescarias e a composição qualitativa e quantitativa das capturas (Petrere Jr., 1985; Isaac \& Barthem, 1995).

Nas últimas três décadas, com o declínio dos estoques de algumas das espécies de maior valor comercial como pirarucu (Arapaima gigas) e tambaqui (Colossoma macropomum) (Isaac \& Ruffino, 1996; Queiroz \& Sardinha, 1999), os pescadores de centros como Manaus começaram a freqüentar pesqueiros em rios mais distantes, o que provocou o aumento do raio de ação de sua frota pesqueira. Segundo Petrere Jr. (1978) os deslocamentos dos barcos alcançavam então normalmente até $500 \mathrm{~km}$ de distância do local de desembarque. Quanto à frota que abastece Manaus, capital do Estado, esse deslocamento se dá para pesqueiros localizados na bacia de tributários do rio Amazonas como Purus, Juruá e Madeira (Batista \& Petrere Jr., 2003).

O rio Madeira é explotado conjuntamente pelas frotas pesqueiras do Amazonas, Pará e Rondônia (Goulding, 1979; Isaac \& Barthem, 1995; Soares \& Junk, 2000). Sua importância é grande, sendo responsável por aproximadamente $15 \%$ de todo o desembarque em Manaus no período de 1994 a 1996 (Batista \& Petrere Jr., 2003). A frota comercial local é composta por barcos, que efetuam suas capturas na calha dos rios e por canoas motorizadas que explotam igarapés e lagos (Goulding, 1979; Cardoso, 2005). Em relação aos agentes de produção envolvidos na atividade, Cardoso (2005) identificou três agentes de produção atuando nos desembarques da pesca comercial de um município da região do Médio rio Madeira sendo os mesmos: pescadores de barcos, canoas motorizadas e compradores de pescado.

Devido a existência de lacunas nas informaçōes sobre a produção de pescado que ocorre em regiōes da bacia amazônica distantes dos principais centros de desembarque, o presente trabalho teve como objetivo analisar a pesca comercial realizada na região do Médio rio Madeira, tendo como área focal o município de Manicoré, identificando as espécies ou grupo de espécies explotadas, os locais de captura e sua contribuição para o abastecimento local de pescado, o que permitirá aos gerenciadores da atividade pesqueira a tomada de medidas que possam manter a sustentabilidade no uso dos recursos nessa região.

\section{MATERIAL E MÉTODOS}

\section{LOCAL DE COLETA}

O município de Manicoré está localizado na porção sudeste do Estado do Amazonas, região do Médio rio Madeira (Figura 1) e tem aproximadamente $48.282 \mathrm{~km}^{2}$ de extensão, com uma população residente de 44.327 habitantes (IBGE, 2007). O município tem sua economia baseada em atividades do setor primário tais como a agricultura, extrativismo vegetal e a pesca (ICOTI, 1995).

\section{COLETA DE DADOS}

Dados de desembarque pesqueiro foram coletados diariamente no ano de 2002, no período da manhã e da tarde, por intermédio de questionário estruturado, aplicados aos pescadores após a comercialização do pescado no porto de desembarque da Colônia de Pescadores Z-20, sediada em Manicoré. Foram tomadas informaçôes sobre o peso total por espécie de pescado desembarcado, ambiente de pesca (rio, lago, igarapé), espécie ou grupo de espécie capturada e agente de produção (barcos de pesca, canoa motorizada, comprador) envolvido com o desembarque. Para verificar a relação

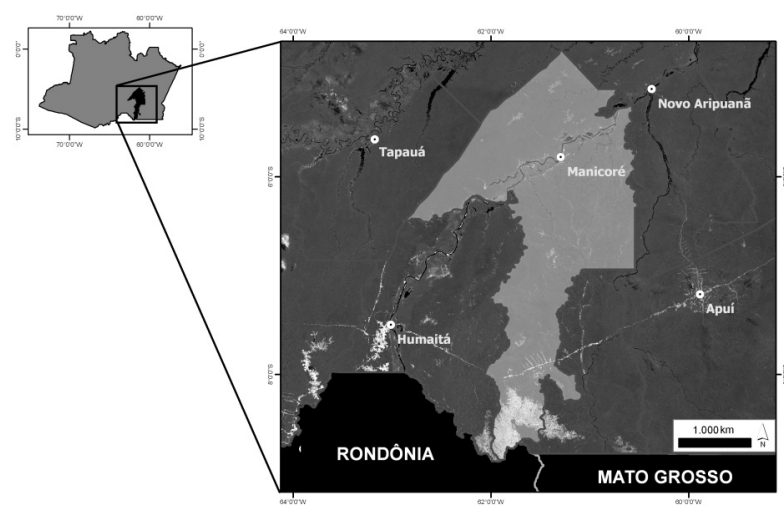

Figura 1 - Área de estudo 
das capturas com o ciclo hidrológico anual, dados da cota mensal do nível do rio Madeira (estação de Manicoré) foram adquiridos junto a Agência Nacional de Águas (ANA).

\section{ANÁLISE ESTATÍSTICA}

Os dados coletados foram submetidos à estatística descritiva (Beiguelman, 2002), para cálculo de média, desvio padrão $( \pm)$ e frequiência de explotação dos ambientes. Para efeito de análise, as capturas realizadas em praias, poços e paranás foram agrupados para o ambiente rio; as capturas realizadas em igapós foram agrupadas ao ambiente lago.

\section{RESULTADOS}

\section{ASPECTOS DO DESEMBARQUE}

Aproximadamente 225,4 toneladas ( $\mathrm{t}$ ) de pescado foram produzidas no ano de 2002, decorrente de 668 expediçóes de pesca no município de Manicoré. Pescadores de canoas motorizadas efetuaram o maior número de expediçôes (Tabela 1). Porém em termos de volume de produção, os pescadores de barcos de pesca foram os que efetuaram maior captura de pescado. O número médio de expediçóes de pesca por mês foi de 17,8 $( \pm 6,1), 30,8( \pm 18,1)$ e 7,6 $( \pm 3,5)$ para barcos, canoas e compradores, respectivamente.

Ao longo de um ciclo anual, foram identificados três picos de produção de pescado (Figura 2): no mês de abril, período da cheia, em julho e agosto, época de vazante e o terceiro nos meses de novembro e dezembro, início da enchente. $\mathrm{O}$ volume médio de pescado desembarcado foi de $18,87( \pm 8,69) \mathrm{t} / \mathrm{mês}$, com valor máximo de 30,97 t no mês de dezembro e mínimo de 9,02 $\mathrm{t}$ em junho. Barcos de pesca desembarcaram em média $11,21( \pm 7,50) \mathrm{t} / \mathrm{mês}$, enquanto canoas desembarcaram 5,44 $( \pm 3,72) \mathrm{t} / \mathrm{mês}$ e compradores $2,22( \pm 1,20) \mathrm{t} / \mathrm{mês}$.

Durante a maior parte do ano, a produção dos barcos superou a produção dos demais agentes, com exceção dos meses de março, setembro e outubro, durante o pico da cheia e seca quando a produção das canoas motorizadas ultrapassou a dos barcos. Os desembarques dos compradores ocorreram durante dez meses, não sendo registrado desembarque nos meses de abril e maio. $\mathrm{O}$ maior volume de produção deste agente ocorreu no período de janeiro a março.

Tabela 1 - Produção de pescado e número de expedições de pesca por agente de produção envolvido nos desembarques.

\begin{tabular}{lllll}
\hline Agente & Produção (t) & $(\%)$ & Expedições & $(\%)$ \\
\hline Barco de pesca & 134,3 & 59,6 & 214 & 32,0 \\
$\begin{array}{l}\text { Canoa } \\
\text { motorizada }\end{array}$ & 65,2 & 28,9 & 370 & 55,4 \\
Comprador & 25,9 & 11,5 & 84 & 12,6 \\
Total & 225,4 & 100 & 668 & 100 \\
\hline
\end{tabular}

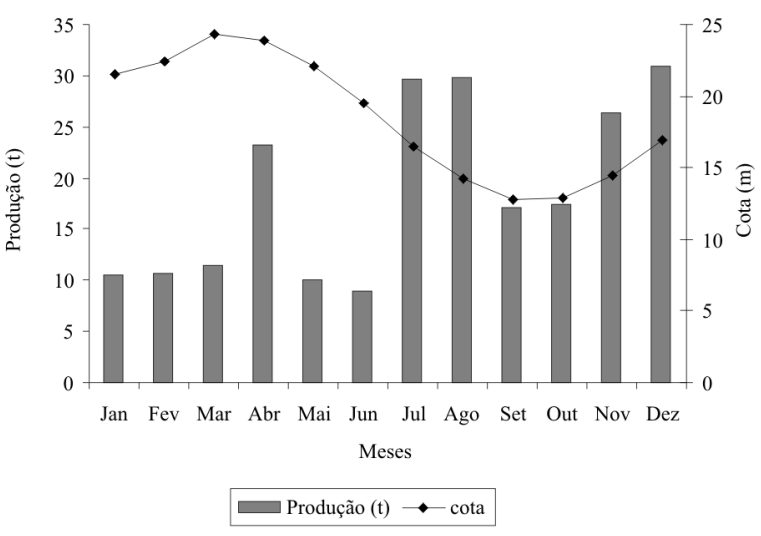

Figura 2 - Desembarque mensal de pescado no município de Manicoré.

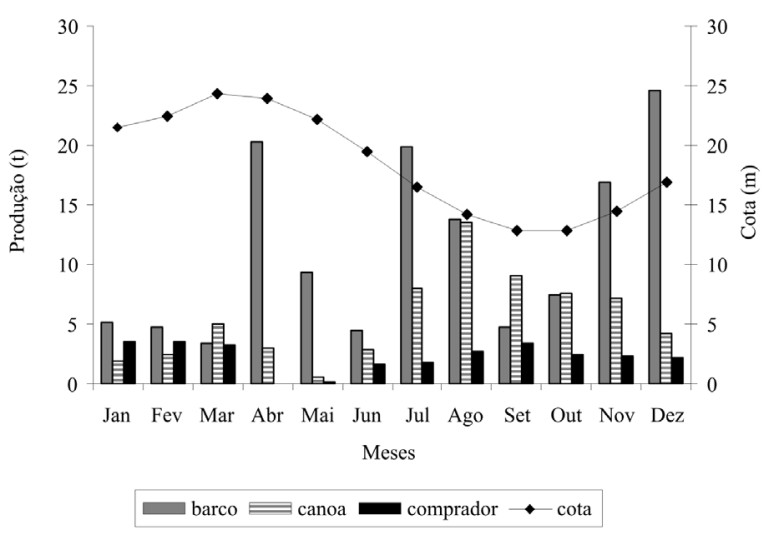

Figura 3 - Produção anual de pescado por agente de produção.

\section{PRINCIPAIS ESPÉCIES DESEMBARCADAS}

Foram registradas 32 espécies ou grupos de espécies nos desembarques da pesca comercial no município, sendo doze espécies ou grupos de espécies de peixes da ordem Characiformes, nove sedentários (Perciformes, Osteoglossiformes) e onze espécies de bagres (Siluriformes). Jaraqui (Semaprochilodus spp), pacu (Mylossoma duriventre), curimatá (Prochilodus nigricans), sardinha (Triportheus spp) e jatuarana (Brycon spp) foram as espécies com o maior volume de desembarque, representando $75 \%$ da produção.

Dentre as espécies capturadas, apenas pacu e branquinha apresentaram desembarque durante todos os meses do período estudado. Pacu, curimatá, sardinha, jatuarana, caparari e aracu tiveram seus picos de produção nos meses de julho e agosto (Tabela 2). O jaraqui, responsável por $24 \%$ dos desembarques, apresentou picos de produção nos meses de abril e dezembro. 
Tabela 2 - Principais espécies desembarcadas (em toneladas) no município de Manicoré.

\begin{tabular}{|c|c|c|c|c|c|c|c|c|c|c|c|c|c|c|c|}
\hline Nome comum & Espécie & Jan & Fev & Mar & Abr & Mai & Jun & Jul & Ago & Set & Out & Nov & Dez & Total (t) & $\%$ \\
\hline Jaraqui & Semaprochilodus spp & 1,85 & 0,67 & - & 16,74 & 5,35 & 0,81 & - & 0,03 & - & 0,32 & 8,48 & 20,29 & 54,53 & 24,2 \\
\hline Pacu & Mylossoma duriventre & 1,49 & 4,07 & 2,76 & 1,24 & 0,72 & 1,96 & 3,75 & 7,45 & 5,11 & 5,23 & 6,48 & 3,51 & 43,8 & 19,4 \\
\hline Curimatá & Prochilodus nigricans & - & 0,84 & - & 0,14 & - & 1,73 & 7,97 & 9,60 & 2,30 & 3,00 & 0,38 & 0,20 & 26,2 & 11,6 \\
\hline Sardinha & Triportheus spp & 2,55 & 1,78 & - & - & - & 1,11 & 4,02 & 6,24 & 2,76 & 2,98 & 2,95 & 1,32 & 25,7 & 11,4 \\
\hline Jatuarana & Brycon spp & 1,10 & 0,07 & 3,09 & 2,07 & 0,95 & 0,22 & 10,62 & 0,27 & - & 0,04 & - & - & 18,4 & 8,2 \\
\hline Branquinha & Curimatidae & 1,92 & 2,19 & 4,43 & 2,13 & 2,04 & 0,38 & 0,12 & 0,44 & 0,36 & 0,03 & 1,42 & 1,71 & 17,2 & 7,6 \\
\hline Dourada & $\begin{array}{l}\text { Brachyplatystoma } \\
\text { rousseauxii }\end{array}$ & 0,07 & - & - & - & - & 0,35 & 0,06 & 1,10 & 2,18 & 0,90 & 1,28 & 0,91 & 6,8 & 3,0 \\
\hline Caparari & $\begin{array}{l}\text { Pseudoplatystoma } \\
\text { tigrinum }\end{array}$ & 0,42 & - & - & - & - & - & - & 1,94 & 1,10 & 0,53 & 0,20 & 0,20 & 4,4 & 1,9 \\
\hline Aracu & Anostomidae & 0,65 & 0,14 & 0,20 & 0,53 & 0,11 & 0,29 & 0,70 & 1,06 & - & - & 0,45 & 0,00 & 4,1 & 1,8 \\
\hline Surubim & $\begin{array}{l}\text { Pseudoplatystoma } \\
\text { fasciatum }\end{array}$ & 0,03 & 0,10 & - & - & - & 0,17 & 0,06 & 0,43 & 0,49 & 1,30 & 0,22 & 0,73 & 3,5 & 1,6 \\
\hline- & Outras espécies & 0,46 & 0,57 & 1,02 & 0,31 & 0,79 & 1,99 & 2,09 & 1,33 & 2,83 & 2,66 & 4,59 & 2,09 & 20,7 & 9,2 \\
\hline & Total (t) & 10,54 & 10,42 & 11,51 & 23,16 & 9,95 & 9,02 & 29,39 & 29,89 & 17,15 & 16,99 & 26,44 & 30,97 & 225,4 & 100 \\
\hline
\end{tabular}

Em relação ao local de captura das principais espécies em termos de produção desembarcada, predominaram as capturas efetuadas nos rios (Figura 4). Apenas branquinha e pacu apresentaram uma maior produção proveniente dos lagos. $\mathrm{O}$ ambiente igarapé apresentou maior importância à captura de branquinha, aracu e surubim.

\section{AMBIENTES DE PESCA}

Foram identificados 32 ambientes de pesca nos desembarques que ocorreram no município no período estudado. Os rios Madeira (29,5\%), Manicoré $(16,2 \%)$ e Atininga (8,0\%), os lagos Acará $(9,8 \%)$ e Boquerão $(8,8 \%)$ e o igarapé Matupiri $(8,1 \%)$ foram os principais destinos das expediçôes de pesca.

As expediçóes de pesca para o ambiente rio foram mais freqüentes durante oito meses do ano (Figura 5), enquanto que as expediçôes para o ambiente lago foram superiores aos demais ambientes no período de março a abril e apresentou

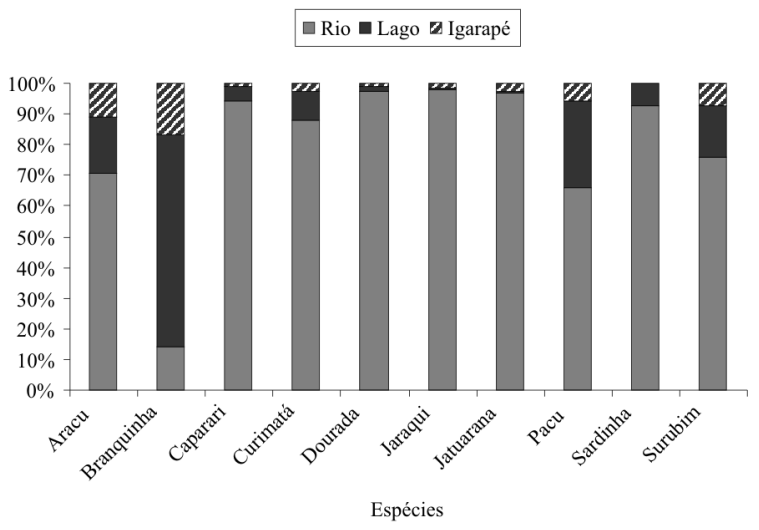

Figura 4 - Ambientes de captura das principais espécies de pescado capturadas em Manicoré.

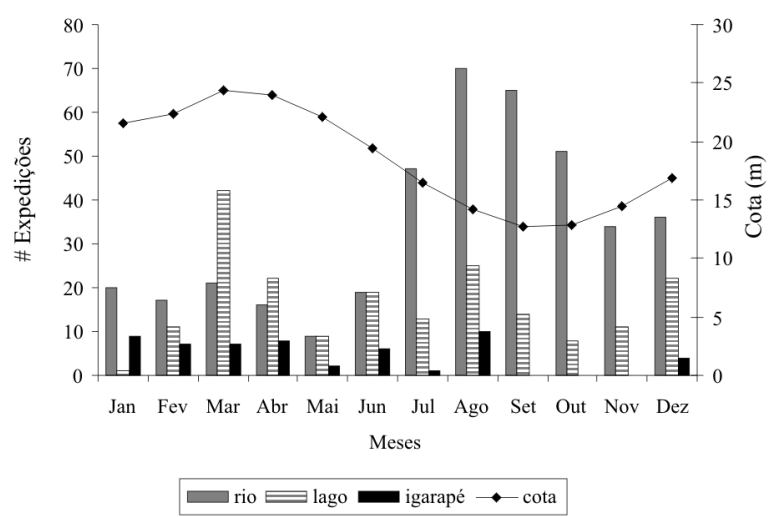

Figura 5 - Número mensal de expedições de pesca por local de captura (n $=656)$.

número de expediçôes igual a dos rios em maio e junho. $\mathrm{O}$ ambiente igarapé não foi utilizado para as expedições durante o período de setembro a novembro.

\section{DISCUSSÃO}

O desembarque ocorrido em Manicoré seguiu o padrão existente no Médio Solimões, na Amazônia Central e no Médio Amazonas, onde a maior parte da produção permanece concentrada em poucas espécies ou grupo de espécies com predominância acentuada de peixes migradores da ordem Characiformes (Merona \& Bittencourt, 1988; Bittencourt \& Cox-Fernandes, 1990; Batista \& Petrere Jr., 2003; Viana, 2004). Não se identificou no desembarque local a participação expressiva, em termos de volume produzido, de espécies sedentárias como tucunaré (Cichla spp) e aruanã (Osteoglossum bicirrhosum). Isso pode ter ocorrido devido a baixa utilização 
do ambiente lago pelos agentes de produção de maior poder de pesca (Cardoso \& Freitas, 2007).

Santos (1986/87) e Boischio (1992) relataram que os desembarques ocorridos na década de 1980-90 em Porto Velho, principal centro de desembarque do rio Madeira, também foram constituídos em sua maioria por Characiformes, embora tenham demonstrado que dourada e tucunaré foram responsáveis conjuntamente por $15 \%$ da produção total. Quando se compara a produção anual de pescado de Manicoré com a de Porto Velho, se observa que a mesma representou somente $24 \%$ dos desembarques ocorridos nessa capital (Boischio, 1992). Em comparação à produção de pescado na calha do rio Solimôes/Amazonas, dos 13 municípios amazonenses onde o Projeto de Manejo dos Recursos Naturais da Várzea - PROVÁRZEA efetuou o acompanhamento do desembarque, a produção local superou apenas a de Alvarães (Médio Solimões) que foi de 139,97 t para o mesmo período (PROVÁRZEA, 2005).

Com relação ao período de maior produção de pescado, os resultados apresentados neste trabalho foram corroborados por Cardoso (2005) que também demonstrou que os picos de desembarque existentes no município ocorreram no período de seca e durante o pico da cheia (mês de abril), padrão também descrito por Goulding (1979) para os desembarques do Alto rio Madeira. Em relação ao volume de produção os valores apresentados neste estudo foram menores que os apresentados por Cardoso \& Freitas (2007) para a mesma regiāo. Considerando que os dados apresentados por Cardoso $\&$ Freitas (2007) foram referentes ao período compreendido entre junho de 2003 e maio de 2004, se observa que a produção pesqueira local apresenta uma tendência de aumento no volume produzido e na utilização de locais de captura.

Uma característica peculiar observada nesse ano foi a ausência de expediçôes de pesca para o ambiente igarapé no período da seca, uma vez que esse ambiente é explotado com maior freqüência por pescadores de canoas motorizadas (Cardoso, 2005) e a produção desse agente superou a dos outros agentes em alguns meses do ano, especialmente no período da seca. A ausência de expediçôes para esse ambiente se deve em parte pela redução do corpo aquático devido a descida das águas e presença de predadores naturais que podem danificar os apetrechos. Por outro lado, nesta época os cardumes são mais freqüentes na calha principal do rio Madeira e o esforço de pesca da frota se concentra principalmente nesse ambiente (Goulding, 1979; Cardoso \& Freitas, 2007) com viagens durando menos de um dia (Cardoso, 2005), o que torna a pesca no ambiente rio mais favorável em termos econômicos.

Em termos de volume desembarcado, o maior volume de produção identificado para os barcos em relação aos demais agentes de produção pode ser atribuído a características como: poder de pesca, maior raio de ação, maior quantitativo de pescadores e capacidade de armazenamento, visto que os barcos dessa frota podem se deslocar entre diversos pesqueiros a procura dos cardumes e armazenar em média $6,1 \mathrm{t}$ de pescado, enquanto pescadores de canoas têm seu deslocamento limitado pela fragilidade da embarcação e principalmente pela baixa capacidade de armazenamento, limitada a um máximo de 2,5 caixas de isopor com capacidade para transportar até $200 \mathrm{~kg}$ pescado por expedição de pesca (Cardoso, 2005).

Porém mesmo com essa limitada capacidade de armazenamento, os desembarques das canoas motorizadas representaram um percentual considerável do total dos desembarques no município, principalmente no período de enchente e cheia quando as capturas dos barcos foram menores. Provavelmente devido à possibilidade de acesso das canoas a um maior número de ambientes, como a floresta inundada, por exemplo, inacessível aos barcos mesmo durante a cheia.

Desembarques efetuados por pescadores de canoas motorizadas também foram identificados em outros locais da bacia amazônica como no Médio Solimões (Viana, 2004) e no Baixo Amazonas (Isaac et al., 2004), onde os desembarques desse agente são maiores no período da seca, mesmo padrão existente na pesca local.

Embora em outros locais da Amazônia existam diversos agentes de produção envolvidos nos vários segmentos da atividade pesqueira (Isaac et al., 2004; Parente \& Batista, 2005), o desembarque neste local foi efetuado por poucos agentes. Não foi identificado, por exemplo, o barco comprador de pescado, agente de produção que é caracterizado por efetuar a compra de pescado nos locais de captura (Isaac et al. 1996) e é comumente encontrado na região do Baixo Amazonas (Isaac et al., 2004) e na Amazônia Central (Faria Jr. \& Batista, 2006).

Vale ressaltar que a atuação de alguns compradores de pescado do local se assemelha à do barco comprador, pois efetuam deslocamentos até os locais de pesca em canoas motorizadas para comprar o pescado (Cardoso, 2005), porém essa ação acontece somente na época da seca. Os compradores também adquirem pescado em outros municípios do rio Madeira (Cardoso, 2005) e revendem no mercado local, comércio que ocorre durante a época de baixa produção de pescado pela frota local, ou quando o mercado está saturado por determinadas espécies e esse agente importa pescado considerado mais nobre, que são transportados até o comércio local por intermédio de barcos de transporte de passageiros.

\section{CONCLUSÕES}

O desembarque de pescado no município apresentou as seguintes características: i) o desembarque foi dominado por 
espécies da ordem Characiformes, principalmente jaraqui (Semaprochilodus spp), curimatá (Prochilodus nigricans) e pacu (Mylossoma duriventre); ii) barcos de pesca foram os responsáveis pelo maior volume de produção e iii) os rios foram os principais locais de captura das espécies com os maiores valores de produção.

\section{AGRADECIMENTOS}

Os autores gostariam de agradecer ao $\mathrm{CNPq}$, pelo suporte financeiro, ao projeto PIATAM pela cessão da infra-estrutura para o desenvolvimento do trabalho, aos MSc. Charles Hanry Faria Jr., Eliete dos Santos Sousa, e aos revisores pelas sugestôes e críticas ao manuscrito, ao Presidente da Colônia de Pescadores Z-20, Antonio Passos Veiga, ao Sr. Antonio Tuffi pelo auxílio na coleta de dados e aos pescadores de Manicoré que com suas informaçōes tornaram possível a conclusão deste trabalho.

\section{BIBLIOGRAFIA CITADA}

Barthem, R.B.; Petrere Jr., M.; Isaac, V.J.; Ribeiro, M.C.L.B.; McGrath, D.G.; Vieira, I.J.A.; Barco, M.V. 1997. A pesca na Amazônia: problemas e perspectivas para seu manejo. In: Valladares-Padua, C.; Bodmer, R.E.; Cullen Jr., L. (Orgs.). Manejo e conservação de vida silvestre no Brasil. Sociedade Civil Mamirauá.CNPq. p. 173-185.

Batista, V.S. 1998. Distribuição, dinâmica da frota e dos recursos pesqueiros da Amazônia Central. Tese de Doutorado. Instituto Nacional de Pesquisas da Amazônia/Fundação Universidade do Amazonas, Manaus, Amazonas. 282p.

Batista, V.S.; Petrere Jr., M. 2003. Characterization of the commercial fish production landed at Manaus, Amazonas State, Brazil. Acta Amazonica, 33(1): 53-65.

Beiguelman, B. 2002. Curso prático de bioestatística. $5^{\mathrm{a}}$. ed. Fundação de Pesquisas Científicas de Ribeirão Preto - FUNPEC. Ribeirão Preto, 274p.

Bittencourt, M.M.; Cox-Fernandes, C. 1990. Peixes migradores sustentam a pesca comercial. Ciência Hoje, 11(64): 20-24.

Boischio, A.A.P. 1992. Produção pesqueira em Porto Velho, Rondônia (1984 - 1989) - alguns aspectos ecológicos das espécies comercialmente relevantes. Acta Amazonica, 22(1): 163-172.

Cardoso, R.S. 2005. A pesca comercial no município de Manicoré (rio Madeira), Amazonas, Brasil. Dissertação de Mestrado, Instituto Nacional de Pesquisas da Amazônia/Fundação Universidade Federal do Amazonas, Manaus, Amazonas. 149p.

Cardoso, R.S.; Freitas, C.E.C. 2007. Desembarque e esforço de pesca da frota pesqueira comercial de Manicoré (Médio rio Madeira), Brasil. Acta Amazonica, 37(4): 605-612.

Faria Jr., C.H.; Batista, V.S. 2006. Repartição da renda derivada da primeira comercialização de pescado na pesca comercial artesanal que abastece Manaus (Estado do Amazonas, Brasil). Acta Sci. Human Soc. Sci., 28(1): 131-136.
Furtado, L.G. 1993. "Reservas pesqueiras", uma alternativa de subsistência e de preservação ambiental: Reflexões a partir de uma proposta de pescadores do médio Amazonas. In: Furtado, L.G.; Mello, A.F.; Leitão, W. (Orgs.). Povos das águas: realidades e perspectivas na Amazônia. MPEG/UFPA. Belém. p. 243-276.

Goulding, M. 1979. A ecologia da pesca no rio Madeira. CNPq/ INPA. Manaus. 172p.

IBGE. 2007. Censo demográfico 2007. (http://www.ibge.gov.br). Acesso 23/01/08.

ICOTI. 1995. Informaçōes básicas sobre o município de Manicoré. Relatório Técnico. Governo do Estado do Amazonas. Manaus. $71 \mathrm{p}$.

Isaac, V.J.; Barthem, R.B. 1995. Os recursos pesqueiros da Amazônia brasileira. Bol. Mus. Para. Emílio Goeldi, Série Antropol. 11(2): 295-339.

Isaac, V.J.; Ruffino, M.L. 1996. Population dynamics of tambaqui (Colossoma macropomum, Cuvier 1818) in the lower Amazon, Brazil. Fisheries Management and Ecology, 3: 315-333.

Isaac, V.J.; Milstein, A.; Ruffino, M.L. 1996. A pesca artesanal no Baixo Amazonas: análise multivariada da captura por espécie. Acta Amazonica, 26(3): 185-208.

Isaac, V.J.; Silva, C.O.; Ruffino, M.L. 2004. A pesca no Baixo Amazonas. In: Ruffino, M.L. (Ed.). A pesca e os recursos pesqueiros na Amazônia brasileira. IBAMA/PROVÁRZEA. p. 185-211.

Merona, B.; Bittencourt, M.M. 1988. A pesca na Amazônia através dos desembarques no mercado de Manaus: resultados preliminares. Memória Sociedad Ciencias Naturales La Salle, 48(Suplemento 2): 433-453.

Queiroz, H.L.; Sardinha, A.D. 1999. A preservação e o uso sustentado dos pirarucus em Mamirauá. In: Queiroz, H.L.; Crampton, W.G.R. (Ed.). Estratégias para manejo de recursos pesqueiros em Mamirauá. Sociedade Civil Mamirauá. MCT/ CNPq. p. 108-141.

Parente, V.M.; Batista, V.S. 2005. A organização do desembarque e o comércio de pescado na década de 1990 em Manaus, Amazonas. Acta Amazonica, 35(3): 375-382.

Petrere Jr., M. 1978. Pesca e esforço de pesca no Estado do Amazonas I - Esforço e captura por unidade de esforço. Acta Amazonica, 8(3): 439-454.

Petrere Jr., M. 1985. A pesca comercial no rio Solimões-Amazonas e seus afluentes: análise dos informes do pescado desembarcado no Mercado Municipal de Manaus (1976-1978). Ciência e Cultura, 37(12): 1987-1999.

PROVÁRZEA. 2005. Estatística pesqueira do Amazonas e Pará2002. IBAMA. Manaus. 84p.

Santos, G.M. 1986/87. Composição do pescado e situação da pesca no Estado de Rondônia. Acta Amazonica,16/17(Suplemento): 43-84.

Santos, G.M. 1999. A pesca no reservatório da Hidrelétrica de Balbina (Amazonas, Brasil). Acta Amazonica, 29(1): 145-163. 


\section{ACTA}

Soares, M.G.M.; Junk, W.J. 2000. Commercial fishery and fish culture of the state of Amazonas: Status and perspectives. In: Junk, W.J.; Ohly, J.J.; Piedade, M.T.F.; Soares, M.G.M. (Eds.). The central Amazon floodplain: Actual use and options for a sustainable management. Backhuys Publishers, Leiden, Netherlands. p. 433-461.

Viana, J.P. 2004. A pesca no Médio Solimões. In: Ruffino, M.L. (Ed.). A pesca e os recursos pesqueiros na Amazônia brasileira. IBAMA/ PROVÁRZEA. p. 245-268.

Recebido em 26/02/2008

Aceito em 14/08/2008 
